June 21, 2002

SNS 107030600-DA0001-ROO

ORNL/TM-2002/125

\title{
Energy-Deposition and Damage Calculations in Core-Vessel Inserts at the Spallation Neutron Source

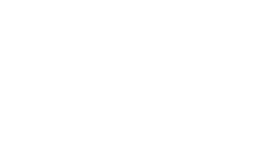




\begin{abstract}
This report was prepared as an account of work sponsored by an agency of the United States government. Neither the United States government nor any agency thereof, nor any of their employees, makes any warranty, express or implied, or assumes any legal liability or responsibility for the accuracy, completeness, or usefulness of any information, apparatus, product, or process disclosed, or represents that its use would not infringe privately owned rights. Reference herein to any specific commercial product, process, or service by trade name, trademark, manufacturer, or otherwise, does not necessarily constitute or imply its endorsement, recommendation, or favoring by the United States government or any agency thereof. The views and opinions of authors expressed herein do not necessarily state or reflect those of the United States government or any agency thereof.
\end{abstract}


SNS 107030600-DA0001-R00

ORNL/TM-2002/125

Nuclear Science and Technology Division (94)

\title{
Energy-Deposition and Damage Calculations in Core-Vessel Inserts at the Spallation Neutron Source
}

\author{
Brian D. Murphy
}

Oak Ridge National Laboratory

Date Published: June 2002

Prepared for the

U.S. Department of Energy

Office of Science

UT-BATTELLE, LLC

managing

Spallation Neutron Source activities at

Argonne National Laboratory

Brookhaven National Laboratory

Thomas Jefferson National Accelerator Facility Lawrence Berkeley National Laboratory

Los Alamos National Laboratory

Oak Ridge National Laboratory

under contract DE-AC05-00OR22725

for the

U.S. DEPARTMENT OF ENERGY 



\section{CONTENTS}

$\underline{\text { Page }}$

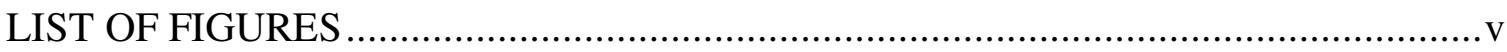

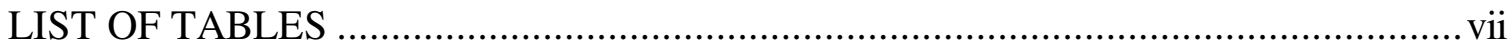

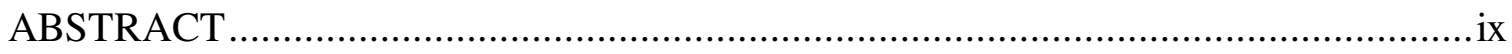

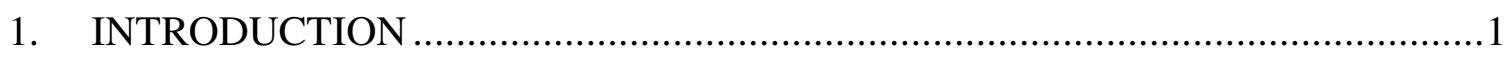

2. THE SINGLE CORE-VESSEL INSERT ………........................................

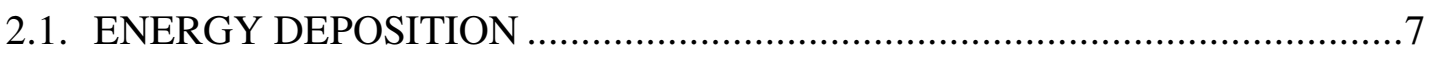

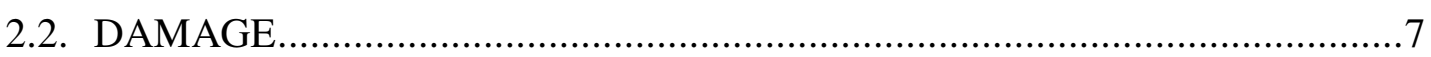

2.3. FLUENCES IN SINGLE CORE-VESSEL INSERT ........................................

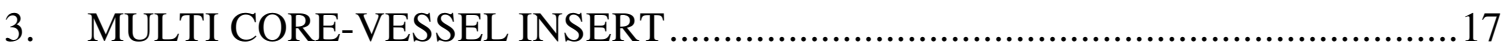

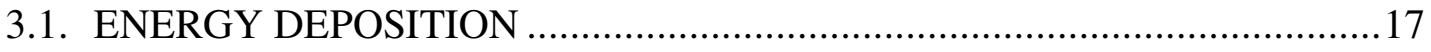

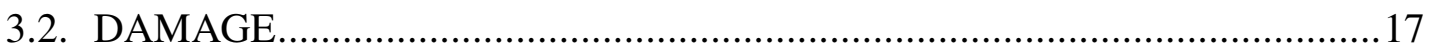

3.3. ALUMINUM WINDOW AND STAINLESS STEEL IN SHUTTER

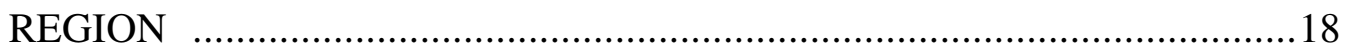

3.4. HARDENED STAINLESS STEEL COMPONENTS....................................21

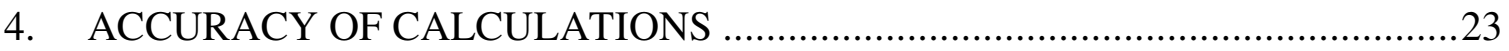

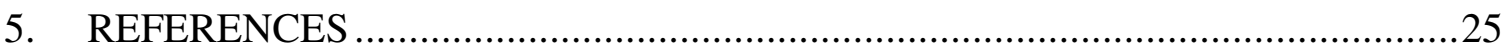




\section{LIST OF FIGURES}

$\underline{\text { Figure }}$

Page

1. A cross section of the single core-vessel insert. Moving outwards from the bore there is a nickel layer, stainless steel, a layer of cadmium, a gap, and the outer stainless steel. The nickel and inner stainless steel form the neutron guide. The stainless steel in the guide may be replaced with glass or aluminum. The scales on the figure are in centimeters. Neither the nickle nor the cadmium can be seen in this drawing. Both are very thin layers (0.005 and 0.02 in., respectively). ..............3

2. A cross section of the multi core-vessel insert towards the front. The sides slope outwards as one moves away from the moderator area. The slope is such that the two sides are at an angle of 4.8 degrees to one another. The surfaces defining the top and bottom of the beam tube are horizontal in all cases. The scales on the figure are in centimeters...

3. Plan view of the single unit in beamline position number 9. The proton beam enters from the bottom of the diagram thus placing the insert in the forward scattering position. The scales on the figure are in centimeters.

4. Energy-deposition rates (heating rates) for the various layers along the sides of the single core-vessel insert containing a stainless steel guide.

5. Energy-deposition rates (heating rates) for the various layers along the sides of the single core-vessel insert containing a glass guide.

6. Energy-deposition rates for a stainless steel beam plug in place of the opening in the single core-vessel insert. This curve can also be used as a conservative estimate for the other stainless steel components of the insert

7. Damage in terms of dpa/year for components of the single core-vessel insert. Results for the insert body, the stainless steel, glass, and aluminum guides are shown. Results are also shown for a stainless steel beam plug in place of the opening. Of course, the insert body and guide results were obtained with the opening in place. Damage values were also estimated for the nickel film. These nickel values are not shown but they are listed in Table 3.

8. The neutron fluence, above $1 \mathrm{keV}$, in one year of operation in the components of the single core-vessel insert. These results show neutrons $/ \mathrm{cm}^{2}$ over $5000 \mathrm{~h}$ of operation with a $2 \mathrm{~mA}$ beam of $1 \mathrm{GeV}$ protons on the target. .......................12

9. The neutron fluence, above $1 \mathrm{MeV}$, in various components of the single corevessel insert during one year of operation..... 


\section{LIST OF FIGURES (continued)}

$\underline{\text { Figure }}$

$\underline{\text { Page }}$

10. Plan view of the multi core-vessel insert in beamline position number 8 . The proton beam enters from the bottom of the diagram thus placing the insert in a forward scattering position. ............................................................. 18

11. Energy deposition along the top sides and bottom of the multi core-vessel insert...19

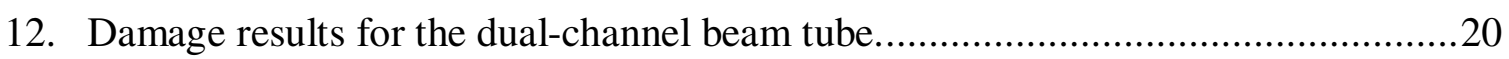




\section{LIST OF TABLES}

Table

Page

1. Summary of energy-deposition in single core-vessel insert. The sides and top/bottom are shown separately and the columns refer to the nickel layer, the stainless steel guide, the cadmium shield and the stainless steel body of the insert. Distance refers to distance from the moderator face.

2. Summary of energy-deposition in single core-vessel insert for three separate cases. No. 1, with a beam plug; No. 2, with a glass neutron guide; and No. 3, with an aluminum neutron guide.

3. Damage results for single core-vessel insert components. In displacements per atom (dpa) for one year's operation $(5000 \mathrm{~h} @ 2 \mathrm{~mA})$. Values are for the sides of all components. Values for a nickel film (or stainless steel guide have been added).

4. Neutron fluences in components of the single core-vessel insert. The upper part of the table is for neutrons above $1 \mathrm{keV}$, the lower part is for neutrons above $1 \mathrm{MeV}$.

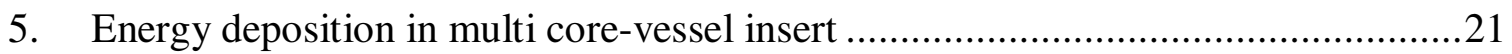

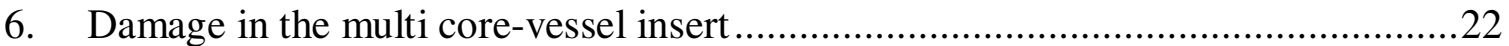




\begin{abstract}
Heat-deposition and damage calculations are described for core-vessel inserts in the target area of the Spallation Neutron Source. Two separate designs for these inserts (or neutron beam tubes) were studied; a single-unit insert and a multi-unit insert. The single unit contains a neutron guide; the multi unit does not. Both units are constructed of stainless steel. For the single unit, separate studies were carried out with the guide composed of stainless steel, glass, and aluminum. Results are also reported for an aluminum window on the front of the insert, a layer of nickel on the guide, a cadmium shield surrounding the guide, and a stainless steel plug in the beam-tube opening.

The locations of both inserts were the most forward positions to be occupied by each design respectively thus ensuring that the calculations are conservative.
\end{abstract}




\section{INTRODUCTION}

This report documents energy-deposition and damage studies carried out on two core-vessel inserts (CVI) at the Spallation Neutron Source (SNS). These CVIs are sometimes referred to as neutron beam tubes. The two CVIs are known as the single and the multi CVIs. The single one is the standard for single-instrument purposes. The multi unit can support two instrument channels. As distinct from the single unit, the multi unit has sides that slope such that the opening in the beam tube increases in the horizontal direction as one moves radially outwards from the moderator/target location.

The single CVI unit, as studied, contained a neutron guide which may be stainless steel, glass, or aluminum and on the inside of which is a thin film of nickel. For the purposes of the study, the single CVI was placed in beam tube position 9. This is a conservative choice in terms of energy deposition (i.e., the beam tube is in the forwardscattering position thus maximizing energy-deposition rates). In this position the unit is mostly irradiated by neutrons from the upstream moderator in the bottom position (below the target). The insert itself is $100 \mathrm{~cm}$ long and its leading edge is located $100 \mathrm{~cm}$ from the center of the moderator unit.

The multi unit was placed in position 8 . This is one position less forward than position 9 but it is the most forward position that will be occupied by a unit with this design. Thus, it is again the most conservative location for this type of CVI. This unit is also $100 \mathrm{~cm}$ in length with its leading edge $100 \mathrm{~cm}$ from the center of the moderator.

Figures 1 and 2 show vertical cross sections of the inserts as one looks from the position of the moderator. The CVI units themselves are horizontally centered in the flight-path region; however, as can be seen in the figures, some of the top and bottom parts are shielded by reflector material. (The figures are from planes perpendicular to the beam-tube axes. The empty spaces to the right and left of the middle parts are the neutron flight-path regions. There is shielding material to the top and bottom of the inserts and this material extends in towards the moderators above and below the flightpath region). As a consequence of this shielding, calculations were performed so that energy-deposition and damage rates for the sides and the top and bottom were obtained separately.

Figure 3 is a plan view that shows the single CVI, moderators, reflector, and shielding. Figure 3 is from a horizontal plane at the height of the center of the flight path and, therefore, it does not show the shielding that extends towards the moderator region. Volume averaged energy-deposition rates were calculated for segments of the beam tube that were $5 \mathrm{~cm}$ in length and for $10 \mathrm{~cm}$ segments farther out. Figures 4 though 7 show results from energy-deposition and damage calculations as a function of radial distance along this unit. 
The studies reported here were carried out via Monte Carlo simulations using version 2.1.5 of MCNPX $!^{1}$ All calculations reported here were performed with metric units and results are reported in watts/cc. However, in order to make some comparisons easier, we report some measurements for the insert components in inches. On the outside, the single CVI is $7 \mathrm{in}$. wide and $9.25 \mathrm{in}$. high. The opening is $3.99 \mathrm{in}$. wide and $4.71 \mathrm{in.} \mathrm{high.} \mathrm{Moving} \mathrm{out} \mathrm{from} \mathrm{the} \mathrm{opening,} \mathrm{there} \mathrm{is} \mathrm{a} \mathrm{nickel} \mathrm{layer,} \mathrm{a} \mathrm{stainless} \mathrm{steel} \mathrm{layer,}$ a cadmium layer, and a gap with thicknesses of $0.005,0.25,0.02$, and 0.0425 in., respectively. Outside of the gap is the stainless steel body of the unit. The nickel and the stainless steel to the inside of the gap form a neutron guide. The cadmium acts as a lowenergy neutron shield that is placed around the guide. We refer to these various components of the insert as the nickel layer, the stainless steel guide, the cadmium shield, the gap, and the stainless steel body of the insert. The guide may also be composed of glass or aluminum and we also report the results of calculations on a unit with a glass guide and with an aluminum guide.

The dimensions of the multi CVI are as follows: At the front (nearest to the target/moderator region), the outside of the unit is 9.25 in. top-to-bottom and it measures $9.82 \mathrm{in.} \mathrm{from} \mathrm{side-to-side.} \mathrm{The} \mathrm{top} \mathrm{and} \mathrm{bottom} \mathrm{walls} \mathrm{are} 2.265$ in. thick. The side walls are $1.0 \mathrm{in}$. thick. All top and bottom surfaces of the unit are horizontal so the opening is constant in the vertical direction. However, the sides of the unit form an angle of 2.4 degrees to the central axis such that the width of the opening increases with distance from the moderator region. 


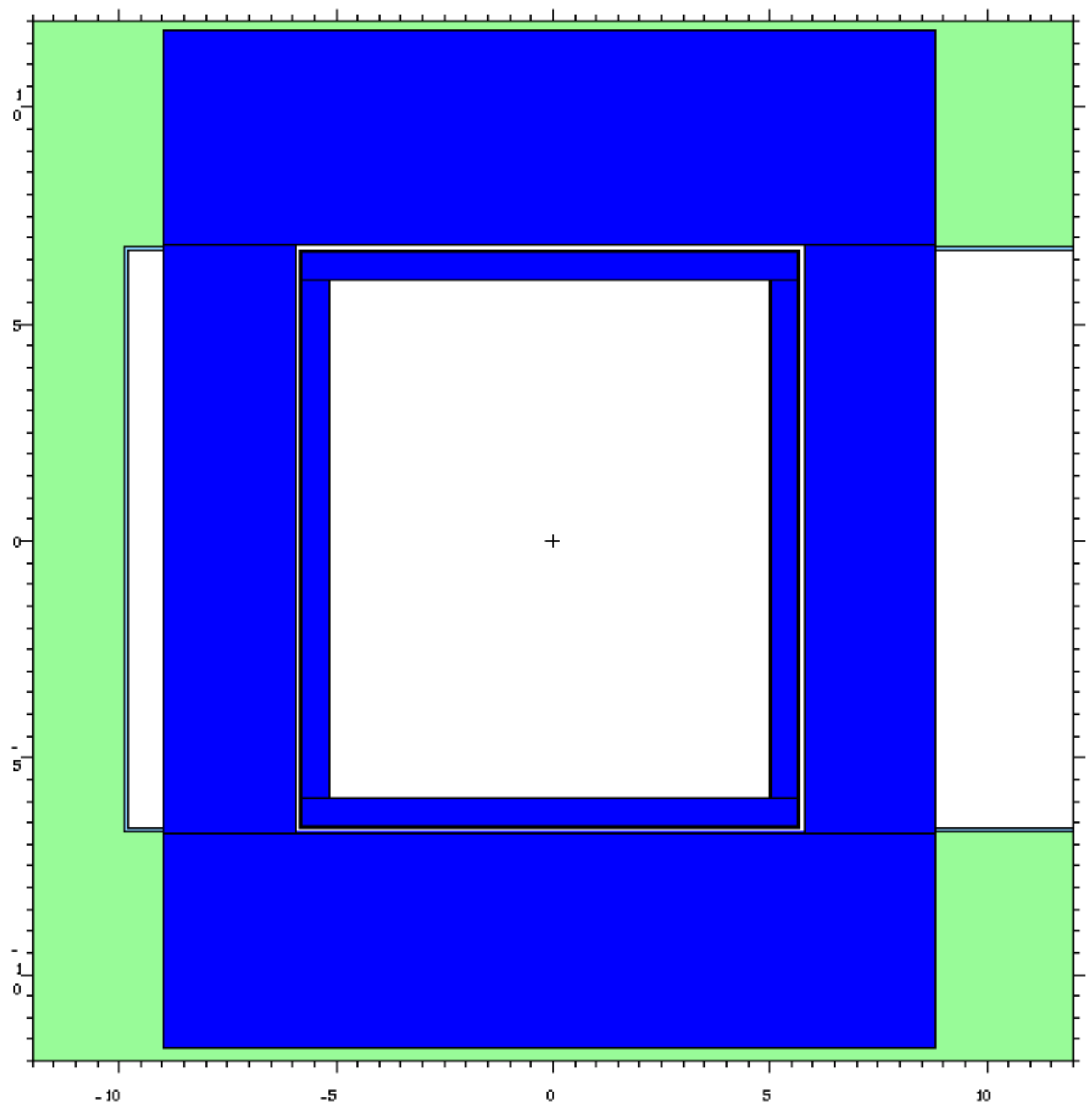

Fig. 1. A cross section of the single core-vessel insert. Moving outwards from the bore there is a nickel layer, stainless steel, a layer of cadmium, a gap, and the outer stainless steel. The nickel and inner stainless steel form the neutron guide. The stainless steel in the guide may be replaced with glass or aluminum. The scales on the figure are in centimeters. Neither the nickle nor the cadmium can be seen in this drawing. Both are very thin layers $(0.005$ and 0.02 in., respectively). 


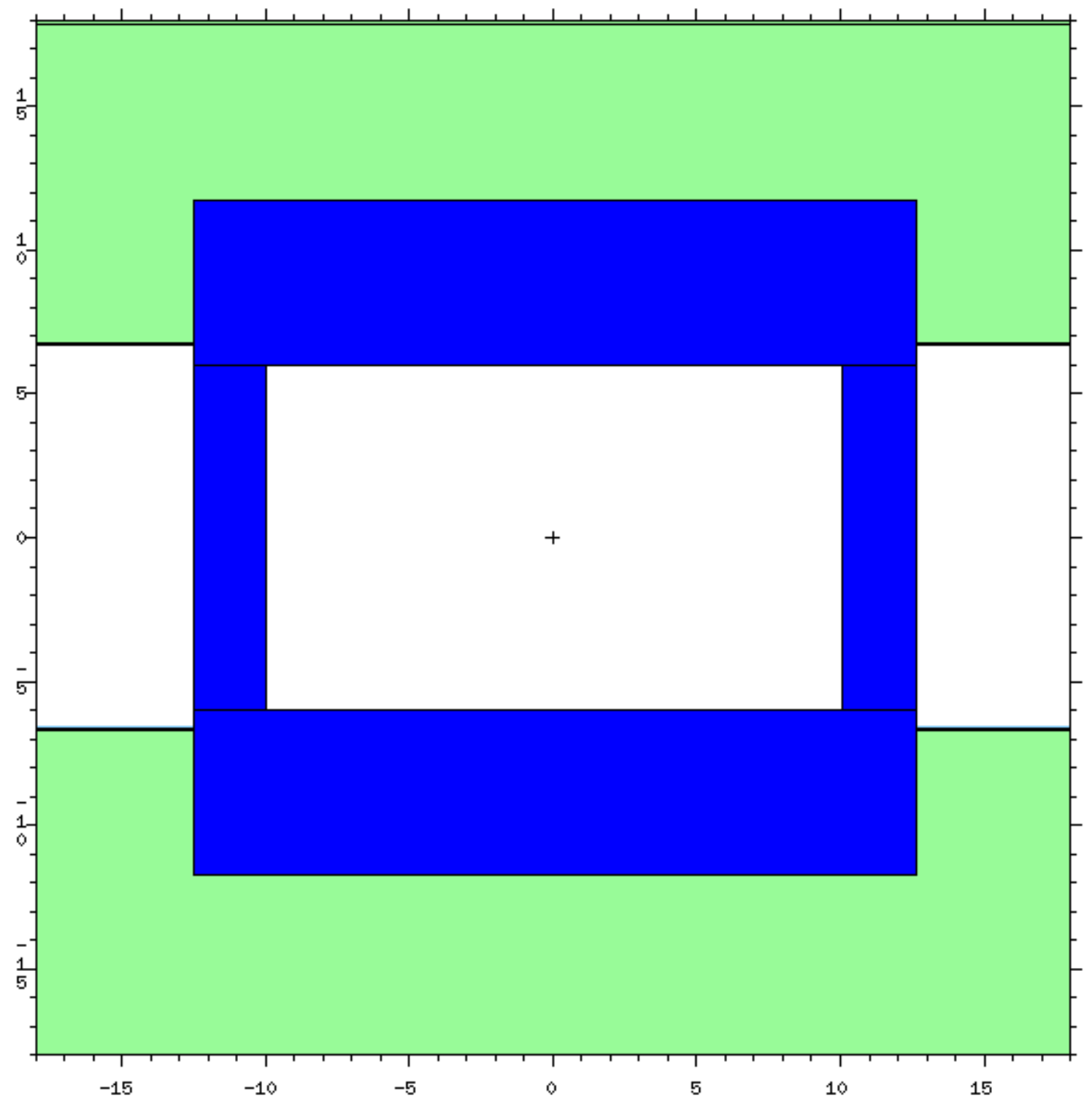

Fig. 2. A cross section of the multi core-vessel insert towards the front. The sides slope outwards as one moves away from the moderator area. The slope is such that the two sides are at an angle of 4.8 degrees to one another. The surfaces defining the top and bottom of the beam tube are horizontal in all cases. The scales on the figure are in centimeters. 


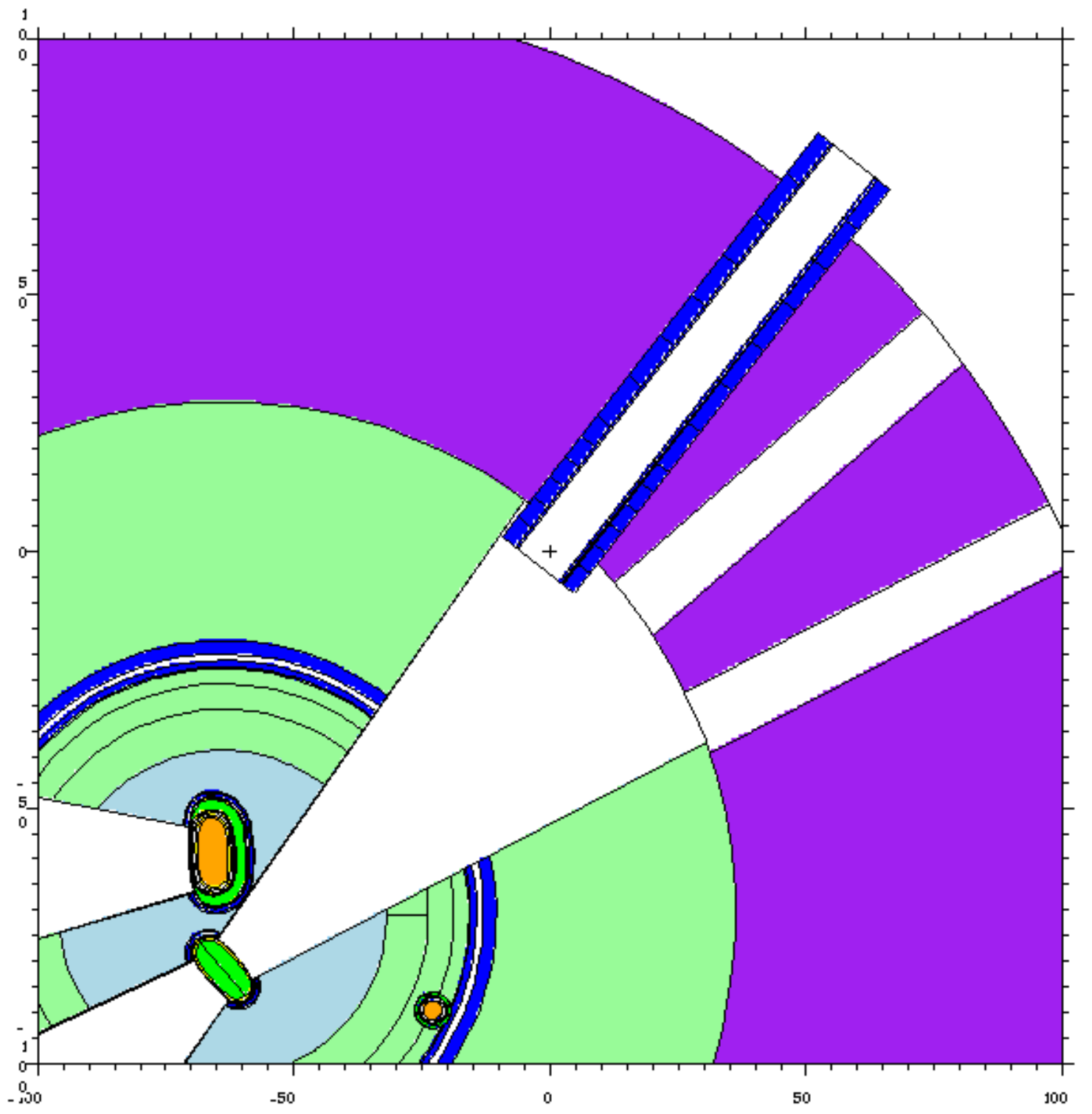

Fig. 3. Plan view of the single unit in beamline position number 9. The proton beam enters from the bottom of the diagram thus placing the insert in the forward scattering position. The scales on the figure are in centimeters. 


\section{THE SINGLE CORE-VESSEL INSERT}

For the single CVI, energy-deposition calculations are reported for all components. Damage calculations are reported for stainless steel, glass, aluminum, and nickel. Flux (or fluence) values are also reported.

\subsection{ENERGY DEPOSITION}

Figure 4 is a plot of energy deposition in watts/cc along the single CVI. These data are for the sides of the unit, which for the insert body, receive more irradiation than the top and bottom parts of the unit (energy-deposition results for the sides and for the top and bottom are shown in Table 1). Figure 4 is for the case where the insert has a stainless steel guide with a thin layer of nickel on the inside of the guide. As indicated, there is a small gap between the guide and the main body of the insert. A thin layer of cadmium is located in this gap. Energydeposition rates are shown for each of these four components (nickel, stainless steel guide, cadmium, and stainless steel insert body). As would be expected, the heating of all components decreases in a consistent manner with distance from the moderator. Because these calculations are stochastic in nature, they have limited precision. The precision issue is obvious if one compares the curve for nickel with that for the stainless steel body of the insert. Because the nickel layer is quite thin, the nickel cells used for flux estimation are about a factor of 300 smaller than the corresponding stainless steel cells. Thus, the nickel cells see relatively fewer events for flux-determination purposes and, as a consequence, the stainless steel results define a much smoother curve.

Figure 5 shows results for the same beam tube with the guide being glass rather than stainless steel. Energy deposition in the guide is noticeably lower when it is composed of glass. For the glass case, the nickel results remain the same to within the precision of the calculations, but, heating of the cadmium and the stainless steel body are slightly higher at locations farther removed from the front. This result might be expected; the cadmium and outer stainless steel are shielded less by the glass guide. When the opening in the insert is filled with a stainless steel plug, the resultant energy-deposition rates can be seen in Fig. 6. Figure 6 shows the rate in the stainless steel plug itself but it also serves as a conservative estimate for the other stainless steel components of the insert with the plug in place.

Energy-deposition values were also calculated for an aluminum guide. The results for the aluminum guide are not shown in Fig. 5; however, they are listed in Table 2 along with the results for a glass guide and a beam plug.

\subsection{DAMAGE}

Damage calculations were performed for the single CVI. Cross sections for these calculations were obtained from Ferguson. ${ }^{2}$ Damage results are reported as displacements per atom (dpa) during one year of operation. This assumes a $2 \mathrm{~mA}$ beam of $1.0 \mathrm{GeV}$ protons on the mercury target over a period of $5000 \mathrm{~h}$. Figure 7 shows damage to the various components of the insert (these results are for the sides of all components). The curves for the body of the unit and for the stainless steel guide are for normal operating conditions, i.e., without the beam plug in place. The damage values for the glass and aluminum guides were obtained from a separate calculation. With a glass or aluminum guide in place the damage to the body of the insert should 
be slightly higher than for the stainless-steel guide case as one moves radially outwards.

However, the damage at the leading edge of the body is the same in both instances. The damage values for the beam plug were obtained in another separate calculation. Damage values are reported numerically in Table 3 . Both the single CVI and the multi CVI (see below) contain hardened steel components. Energy-deposition and damage values for the hardened steel have been determined using a model of the multi unit. These values for the multi unit are conservative and they would also apply to the single unit.

\subsection{FLUENCES IN SINGLE CORE-VESSEL INSERT}

Neutron fluence values have been obtained for the single CVI unit and they are shown graphically in Figs. 8 and 9. Figure 8 shows the results for neutrons above $1 \mathrm{keV}$ and Fig. 9 is for neutrons above $1 \mathrm{MeV}$. These refer to the single unit with a stainless steel guide, an aluminum window, and, of course, no beam plug.

To summarize, the numerical results for the single CVI are listed in Tables 1-4. These tables essentially refer to the results shown graphically in Figs. 4-9.

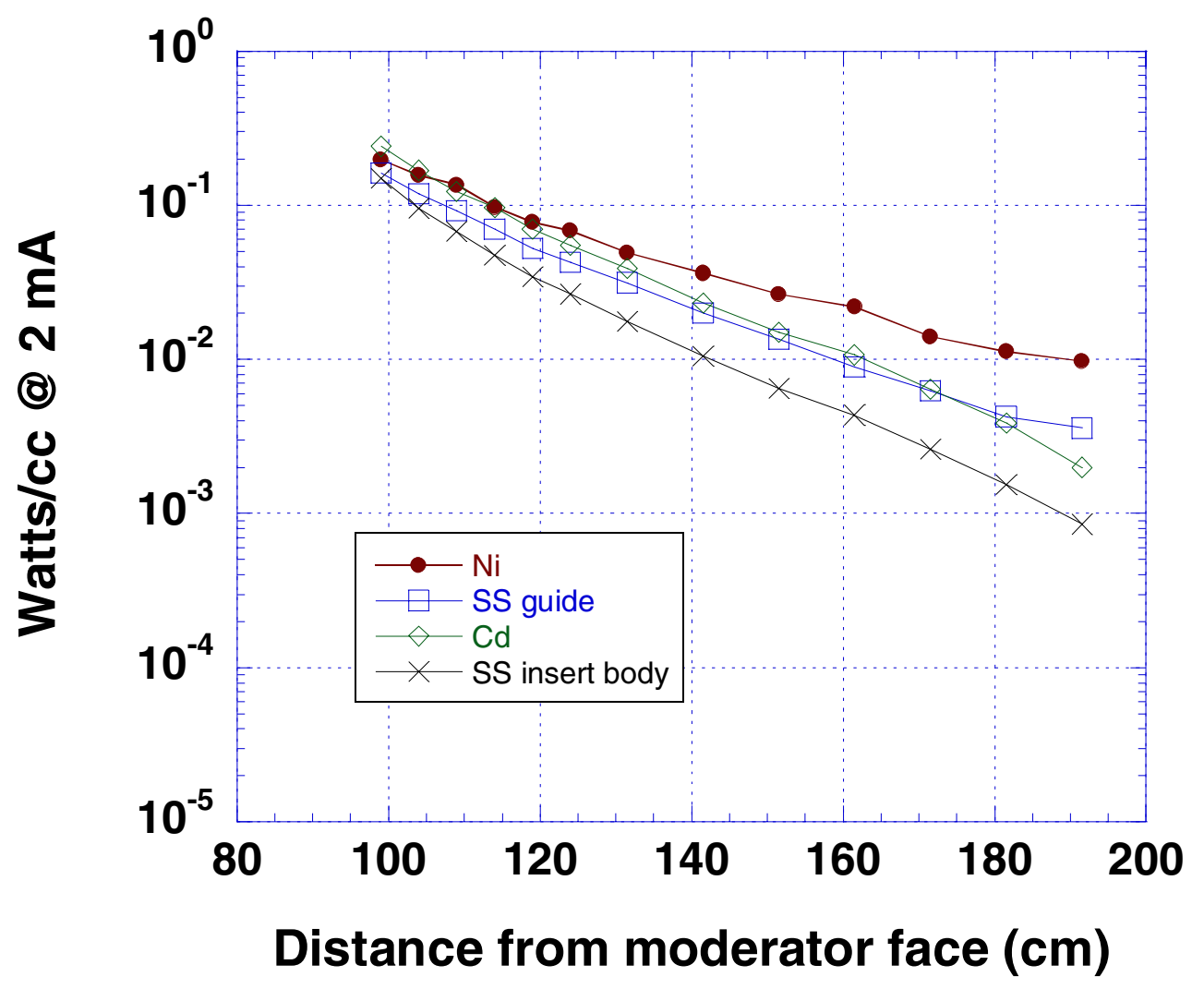

Fig. 4. Energy-deposition rates (heating rates) for the various layers along the sides of the single core-vessel insert containing a stainless steel guide. 


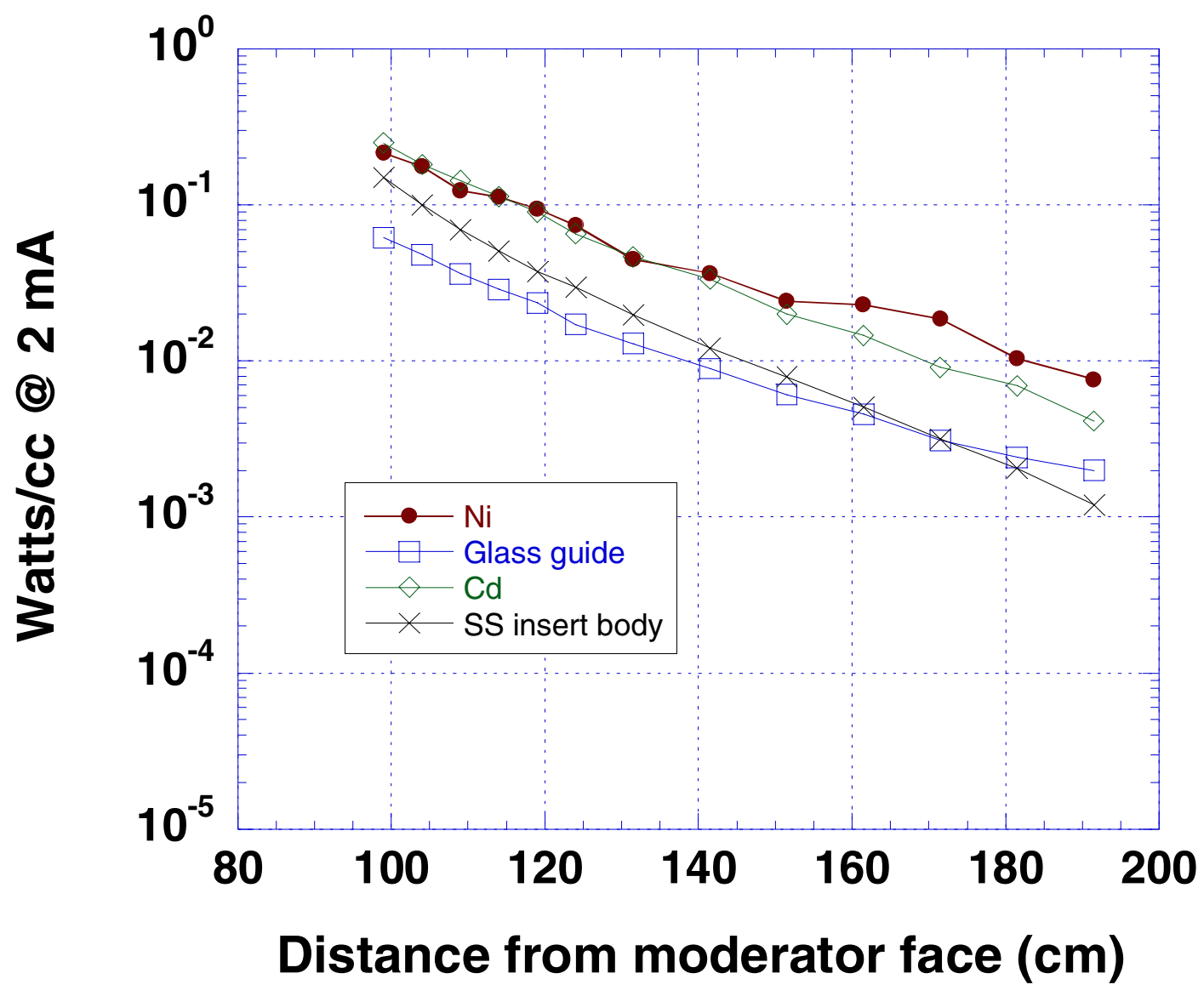

Fig. 5. Energy-deposition rates (heating rates) for the various layers along the sides of the single core-vessel insert containing a glass guide. 


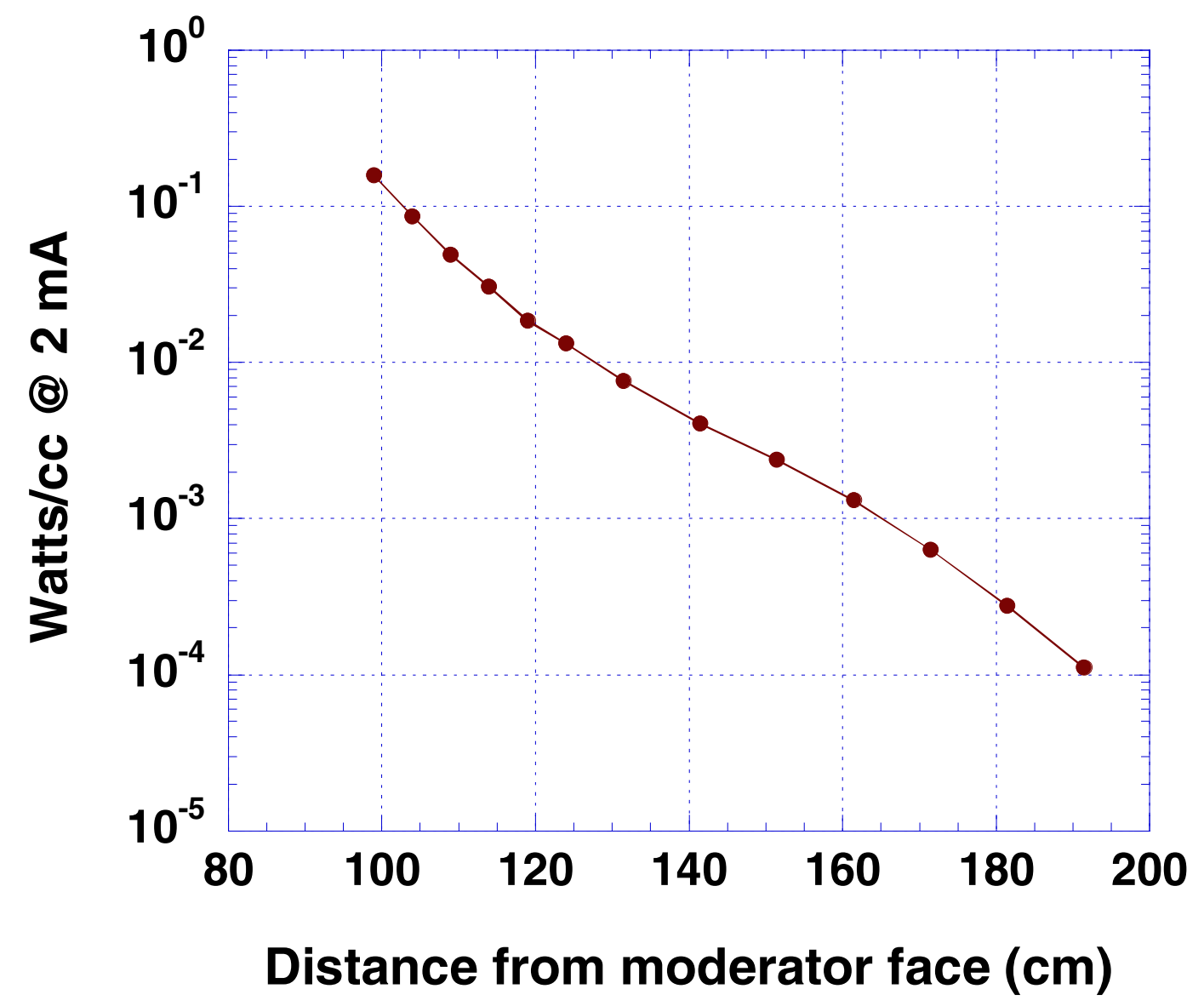

Fig. 6. Energy-deposition rates for a stainless steel beam plug in place of the opening in the single core-vessel insert. This curve can also be used as a conservative estimate for the other stainless steel components of the insert. 


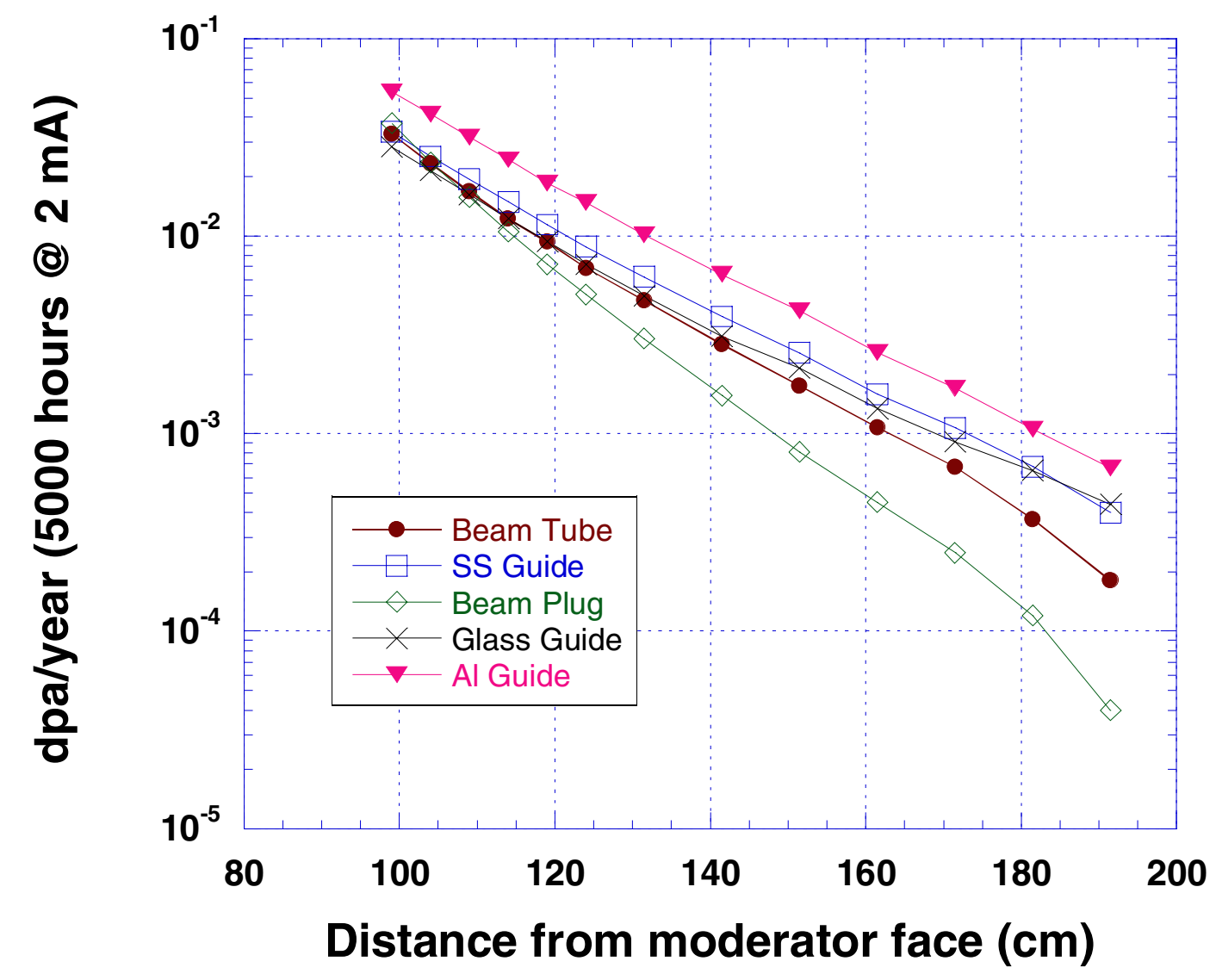

Fig. 7. Damage in terms of dpa/year for components of the single core-vessel insert. Results for the insert body, the stainless steel, glass, and aluminum guides are shown. Results are also shown for a stainless steel beam plug in place of the opening. Of course, the insert body and guide results were obtained with the opening in place. Damage values were also estimated for the nickel film. These nickel values are not shown but they are listed in Table 3. 


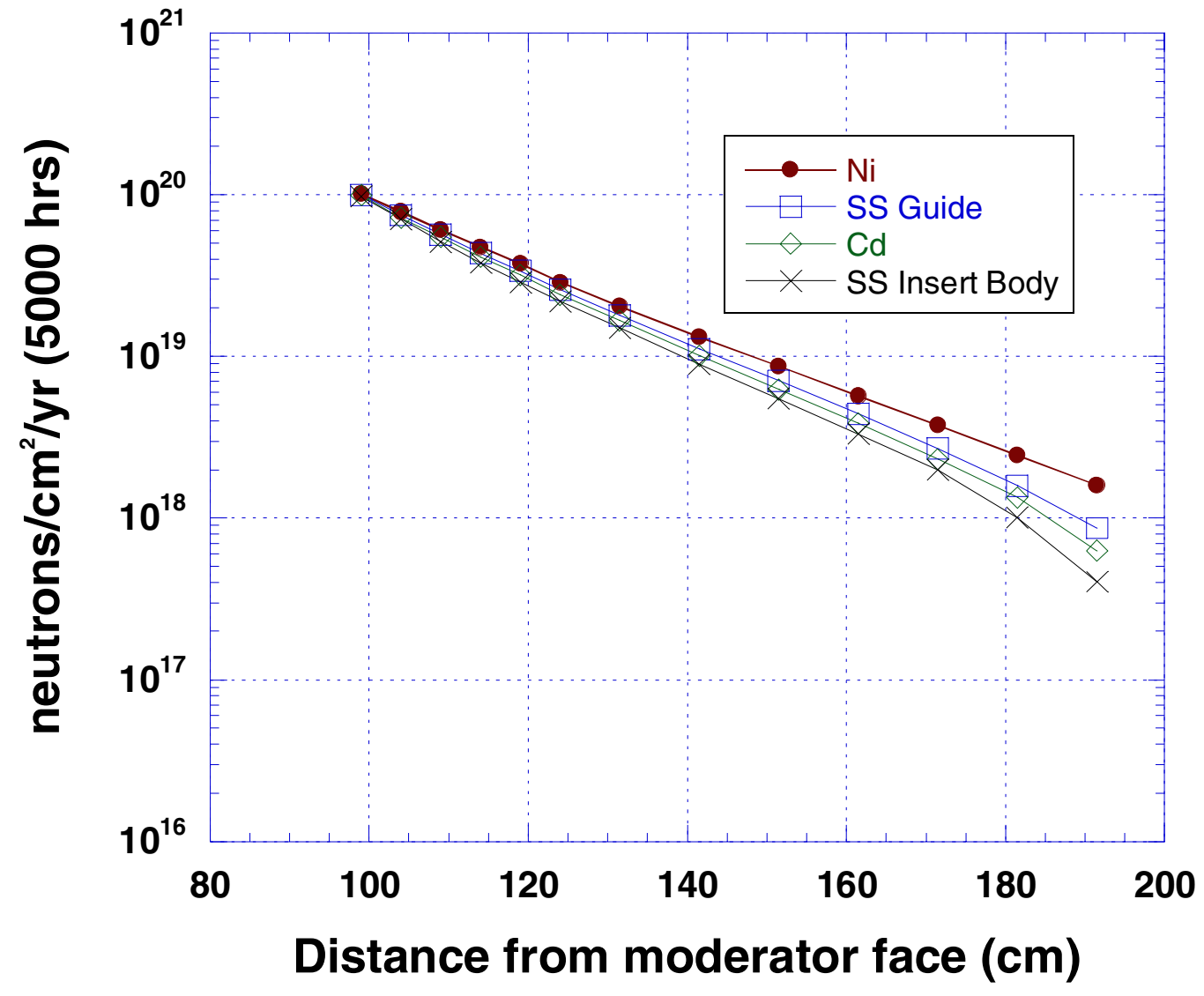

Fig. 8. The neutron fluence, above $1 \mathrm{keV}$, in one year of operation in the components of the single core-vessel insert. These results show neutrons $/ \mathrm{cm}^{2}$ over $5000 \mathrm{~h}$ of operation with a $2 \mathrm{~mA}$ beam of $1 \mathrm{GeV}$ protons on the target. 


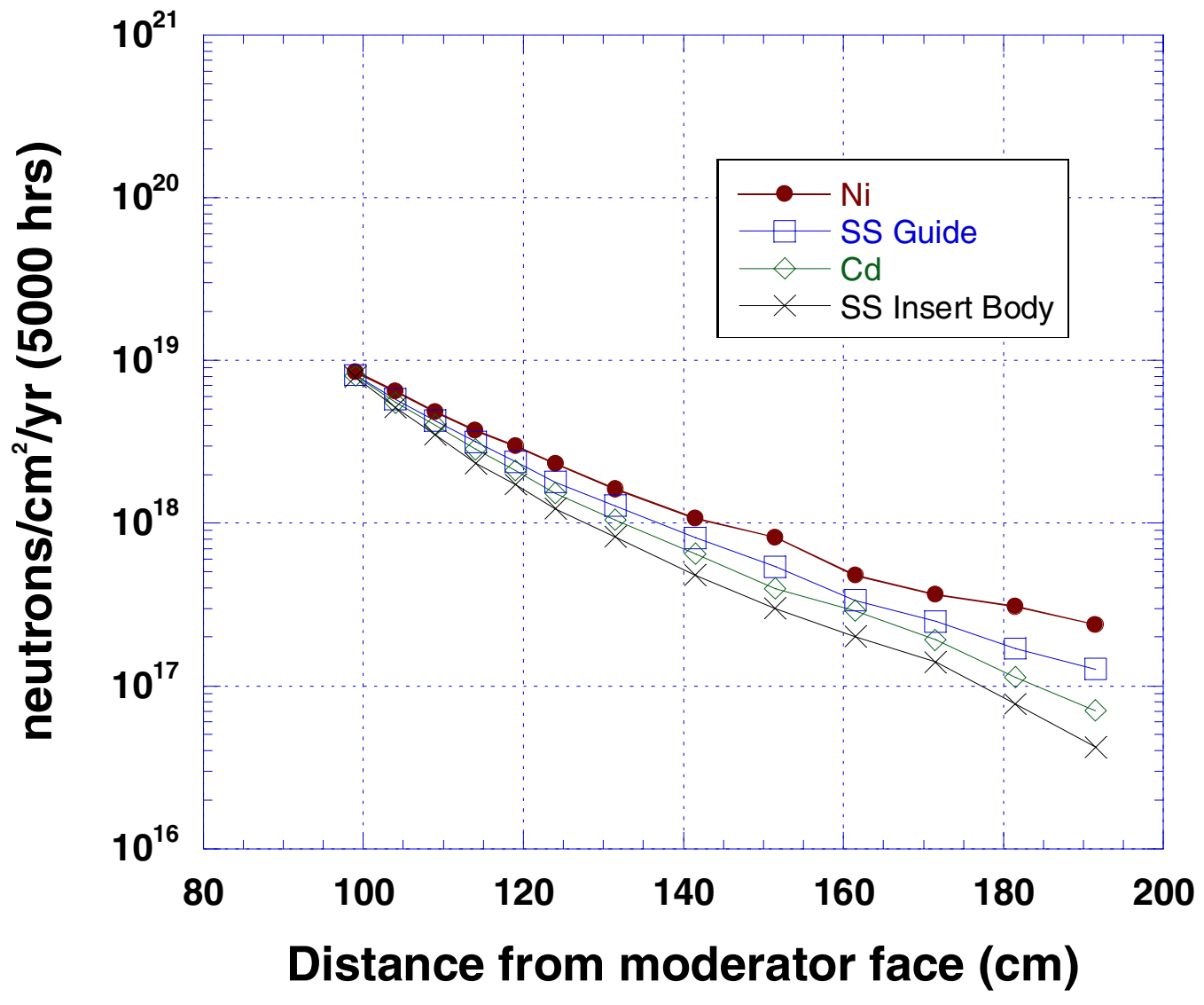

Fig. 9. The neutron fluence, above $1 \mathrm{MeV}$, in various components of the single corevessel insert during one year of operation. 
Table 1. Summary of energy-deposition in single core-vessel insert. The sides and top/bottom are shown separately and the columns refer to the nickel layer, the stainless steel guide, the cadmium shield and the stainless steel body of the insert. Distance refers to distance from the moderator face.

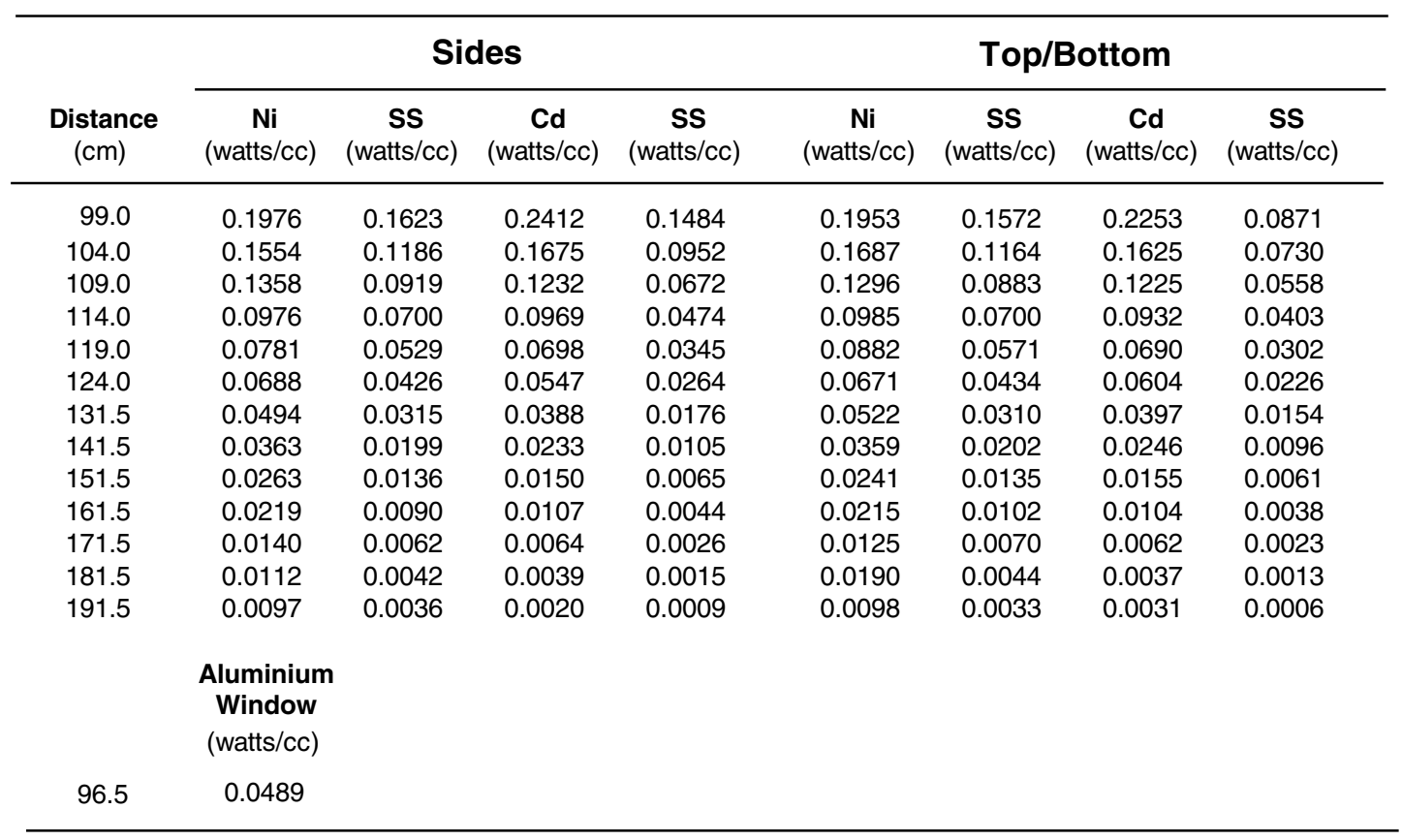

Table 2. Summary of energy-deposition in single core-vessel insert for three separate cases. No. 1, with a beam plug; No. 2, with a glass neutron guide; and No. 3, with an aluminum neutron guide.

\begin{tabular}{cccc}
\hline $\begin{array}{c}\text { Distance } \\
(\mathrm{cm})\end{array}$ & $\begin{array}{c}\text { Plug } \\
\text { (watts/cc) }\end{array}$ & $\begin{array}{c}\text { Glass guide } \\
\text { (watts/cc) }\end{array}$ & $\begin{array}{c}\text { Aluminum guide } \\
\text { (watts/cc) }\end{array}$ \\
\hline 99.0 & 0.15774 & 0.06192 & 0.05775 \\
104.0 & 0.08649 & 0.04803 & 0.04282 \\
109.0 & 0.04876 & 0.03609 & 0.03290 \\
114.0 & 0.03059 & 0.02878 & 0.02622 \\
119.0 & 0.01850 & 0.02358 & 0.02158 \\
124.0 & 0.01314 & 0.01721 & 0.01680 \\
131.5 & 0.00759 & 0.01290 & 0.01274 \\
141.5 & 0.00406 & 0.00897 & 0.00839 \\
151.5 & 0.00235 & 0.00609 & 0.00584 \\
161.5 & 0.00130 & 0.00460 & 0.00439 \\
171.5 & 0.00063 & 0.00312 & 0.00303 \\
181.5 & 0.00028 & 0.00241 & 0.00215 \\
191.5 & 0.00011 & 0.00199 & 0.00141 \\
\hline
\end{tabular}


Table 3. Damage results for single core-vessel insert components. In displacements per atom (dpa) for one year's operation $(5000 \mathrm{~h} @ 2 \mathrm{~mA})$. Values are for the sides of all components. Values for a nickel film (or stainless steel guide) have been added.

\begin{tabular}{ccccccc}
\hline $\begin{array}{c}\text { Stainless } \\
\text { steel } \\
\text { body } \\
\text { (cm) }\end{array}$ & $\begin{array}{c}\text { Stainless } \\
\text { steel } \\
\text { guide } \\
\text { (dpa/year) }\end{array}$ & $\begin{array}{c}\text { Glass } \\
\text { guide } \\
\text { (dpa/year) }\end{array}$ & $\begin{array}{c}\text { Aluminum } \\
\text { guide } \\
\text { (dpa/year) }\end{array}$ & $\begin{array}{c}\text { Stainless } \\
\text { steel } \\
\text { beam plug } \\
\text { (dpa/year) }\end{array}$ & $\begin{array}{c}\text { Nickel } \\
\text { film } \\
\text { (dpa/year) }\end{array}$ \\
\hline 19.0 & 0.03293 & 0.03370 & 0.02846 & 0.05402 & 0.03722 & 0.03320 \\
104.0 & 0.02322 & 0.02537 & 0.02140 & 0.04144 & 0.02375 & 0.02798 \\
109.0 & 0.01691 & 0.01940 & 0.01628 & 0.03178 & 0.01568 & 0.02259 \\
114.0 & 0.01225 & 0.01497 & 0.01230 & 0.02438 & 0.01055 & 0.01689 \\
119.0 & 0.00935 & 0.01147 & 0.00944 & 0.01865 & 0.00722 & 0.01172 \\
124.0 & 0.00692 & 0.00885 & 0.00726 & 0.01479 & 0.00508 & 0.00978 \\
131.5 & 0.00473 & 0.00622 & 0.00498 & 0.01018 & 0.00304 & 0.00661 \\
141.5 & 0.00284 & 0.00391 & 0.00311 & 0.00644 & 0.00156 & 0.00491 \\
151.5 & 0.00175 & 0.00257 & 0.00215 & 0.00420 & 0.00081 & 0.00330 \\
161.5 & 0.00108 & 0.00159 & 0.00135 & 0.00260 & 0.00045 & 0.00196 \\
171.5 & 0.00068 & 0.00107 & 0.00091 & 0.00170 & 0.00025 & 0.00147 \\
181.5 & 0.00037 & 0.00068 & 0.00065 & 0.00106 & 0.00012 & 0.00117 \\
191.5 & 0.00018 & 0.00040 & 0.00044 & 0.00067 & 0.00004 & 0.00079
\end{tabular}

\footnotetext{
Aluminium

window

(dpa/year)
} 
Table 4. Neutron fluences in components of the single core-vessel insert. The upper part of the table is for neutrons above $1 \mathrm{keV}$, the lower part is for neutrons above $1 \mathrm{MeV}$.

\begin{tabular}{|c|c|c|c|c|}
\hline \multirow{2}{*}{$\begin{array}{c}\text { Distance } \\
\text { from moderator } \\
\text { face } \\
(\mathrm{cm})\end{array}$} & \multicolumn{4}{|c|}{ (fluence above $1 \mathrm{keV}$ in 1 year, $5000 \mathrm{~h}$ ) } \\
\hline & Nickel & $\begin{array}{l}\text { Stainless } \\
\text { steel guide }\end{array}$ & Cadmium & $\begin{array}{l}\text { Stainless } \\
\text { steel body }\end{array}$ \\
\hline 99.0 & $1.01235 \mathrm{E}+20$ & $9.98250 \mathrm{E}+19$ & $9.87454 \mathrm{E}+19$ & $9.79121 \mathrm{E}+19$ \\
\hline 104.0 & $7.82819 \mathrm{E}+19$ & 7.45497E+19 & $7.22258 \mathrm{E}+19$ & $7.05678 \mathrm{E}+19$ \\
\hline 109.0 & $6.07984 \mathrm{E}+19$ & 5.71387E+19 & $5.46035 \mathrm{E}+19$ & $5.14610 \mathrm{E}+19$ \\
\hline 114.0 & $4.74842 \mathrm{E}+19$ & 4.37987E+19 & 4.12749E+19 & 3.79793E+19 \\
\hline 119.0 & $3.76485 \mathrm{E}+19$ & 3.39369E+19 & $3.18821 \mathrm{E}+19$ & $2.89064 \mathrm{E}+19$ \\
\hline 124.0 & 2.89705E+19 & $2.59060 \mathrm{E}+19$ & $2.41893 \mathrm{E}+19$ & 2.18037E+19 \\
\hline 131.5 & $2.05491 \mathrm{E}+19$ & $1.80163 \mathrm{E}+19$ & $1.66358 \mathrm{E}+19$ & $1.49632 \mathrm{E}+19$ \\
\hline 141.5 & $1.31708 \mathrm{E}+19$ & 1.10523E+19 & 1.01057E+19 & $8.94624 \mathrm{E}+18$ \\
\hline 151.5 & $8.72412 \mathrm{E}+18$ & $7.02320 \mathrm{E}+18$ & $6.23036 \mathrm{E}+18$ & $5.49826 \mathrm{E}+18$ \\
\hline 161.5 & $5.67760 \mathrm{E}+18$ & $4.38923 E+18$ & $3.86908 \mathrm{E}+18$ & 3.32270E +18 \\
\hline 171.5 & $3.73778 \mathrm{E}+18$ & $2.69805 E+18$ & $2.32633 \mathrm{E}+18$ & $1.99056 \mathrm{E}+18$ \\
\hline 181.5 & $2.46487 \mathrm{E}+18$ & 1.58797E+18 & 1.33437E+18 & $1.01182 \mathrm{E}+18$ \\
\hline 191.5 & $1.60325 \mathrm{E}+18$ & 8.71910E+17 & $6.32527 \mathrm{E}+17$ & $4.04776 \mathrm{E}+17$ \\
\hline \multirow{2}{*}{$\begin{array}{l}\text { Distance } \\
\text { from moderator } \\
\text { face } \\
(\mathrm{cm}) \\
\end{array}$} & \multicolumn{4}{|c|}{ (fluence above $1 \mathrm{MeV}$ in 1 year, $5000 \mathrm{~h}$ ) } \\
\hline & Nickel & $\begin{array}{c}\text { Stainless } \\
\text { steel guide }\end{array}$ & Cadmium & $\begin{array}{l}\text { Stainless } \\
\text { steel body }\end{array}$ \\
\hline 99.0 & $8.54120 \mathrm{E}+18$ & $8.12683 E+18$ & $8.04830 \mathrm{E}+18$ & $7.91964 \mathrm{E}+18$ \\
\hline 104.0 & $6.49173 E+18$ & $5.79282 E+18$ & $5.53812 \mathrm{E}+18$ & $5.11838 \mathrm{E}+18$ \\
\hline 109.0 & $4.84269 \mathrm{E}+18$ & $4.28404 \mathrm{E}+18$ & $4.01270 \mathrm{E}+18$ & $3.50323 E+18$ \\
\hline 114.0 & $3.71108 E+18$ & $3.16685 E+18$ & $2.84696 \mathrm{E}+18$ & $2.34610 \mathrm{E}+18$ \\
\hline 119.0 & $2.98582 E+18$ & $2.39118 \mathrm{E}+18$ & $2.10712 \mathrm{E}+18$ & $1.73411 \mathrm{E}+18$ \\
\hline 124.0 & $2.32490 \mathrm{E}+18$ & 1.79953E+18 & $1.53600 \mathrm{E}+18$ & $1.23017 \mathrm{E}+18$ \\
\hline 131.5 & $1.61316 \mathrm{E}+18$ & $1.27621 \mathrm{E}+18$ & $1.05110 \mathrm{E}+18$ & $8.27082 \mathrm{E}+17$ \\
\hline 141.5 & $1.06883 E+18$ & $8.13554 \mathrm{E}+17$ & $6.48246 \mathrm{E}+17$ & $4.80238 \mathrm{E}+17$ \\
\hline 151.5 & $8.21661 \mathrm{E}+17$ & $5.43835 \mathrm{E}+17$ & $3.96830 \mathrm{E}+17$ & $2.99874 \mathrm{E}+17$ \\
\hline 161.5 & $4.81359 \mathrm{E}+17$ & 3.35374E+17 & 2.91597E+17 & $2.01873 E+17$ \\
\hline 171.5 & 3.64287E+17 & $2.51032 \mathrm{E}+17$ & 1.91727E+17 & $1.40878 \mathrm{E}+17$ \\
\hline 181.5 & 3.07060E+17 & $1.69430 \mathrm{E}+17$ & $1.13528 \mathrm{E}+17$ & $7.79371 E+16$ \\
\hline 191.5 & $2.38728 \mathrm{E}+17$ & $1.26563 \mathrm{E}+17$ & 7.09511E+16 & 4.19698E+16 \\
\hline
\end{tabular}




\section{MULTI CORE-VESSEL INSERT}

Figure 10 is a plan view of the multi CVI located in beamline no. 8. The plane of the figure is through the vertical center of the unit and this is also the vertical center of the flightpath region. Again, some of the upper and lower parts of the insert body are shielded by material located above and below the flight path regions.

Because of the partial shielding of the upper and lower surfaces of this unit, and as was the case with the single insert, we treat the sides separately from the top and bottom surfaces. Since they are not shielded by parts of the inner reflector, the sides will suffer more irradiation than will the top and bottom as was found to be the case for the single unit. The previous plots for the single unit show only results for the sides, but the difference for the top and bottom can be seen in Table 1 in the column that gives results for the stainless steel of the insert body (the nickel, the guide, and the cadmium do not exhibit this difference because they are not partially shielded from the moderator region).

\subsection{ENERGY DEPOSITION}

The results to be presented for the multi unit give heating and damage along the top, the sides, and the bottom separately (unlike the single unit case, the top and bottom are not aggregated together). Keep in mind that the multi unit analyses did not consider a guide and, consequently, more plots pertaining to the unit itself can be presented in one figure. Figure 11 shows the results of energy-deposition (heating) estimates for the multi unit. As was the case with the single unit, the maximum heating occurs along the sides because the inner reflector does not shield them. However, note that the energy deposition is greater along the bottom than along the top of the unit. This is the result of neutrons and gamma rays being preferentially directed downward from the target region. If the calculations were performed for one of the inserts facing the upper moderators, one would expect its upper surface to experience more heating. The energy-deposition results for the multi unit are shown numerically in Table 5. The results at the forward region of the side stainless steel in Table 5 should be compared with the results for the forward region at the side of the single unit (Table 1). Comparing the third column in Table 1 (showing the energy deposition in the stainless steel guide which is open to the void) with the side stainless steel in Table 2 (column 3), one sees that the single unit results are slightly higher. This is probably reflecting the fact that the single unit is in the more forward position.

\subsection{DAMAGE}

Figure 12 shows results from damage calculations for the top, sides and bottom of the multi unit. Again, note that values are greatest for the sides and that the damage along the bottom is slightly greater than that along the top. The damage results for the multi unit are shown numerically in Table 6. 


\subsection{ALUMINUM WINDOW AND STAINLESS STEELS IN SHUTTER REGION}

The multi unit will also contain an aluminum window. Energy-deposition and damage values for the single unit would also apply to the aluminum window in the multi unit. In fact, because the single unit is in a more forward location than is the multi unit (beamline 9 versus beamline 8), the aluminum window values will be conservative. In the shutter region for the multi unit, a stainless steel "nose" is located that forms the leading edge of a separator between the two experimental channels of the multi unit. To estimate energy-deposition and damage values in this region a stainless steel cylinder was located at the back of the unit. The axis of the cylinder was along the central axis of the unit. The cylinder had a radius of $2 \mathrm{~cm}$ and extends from $2 \mathrm{~cm}$ from behind the unit to $7 \mathrm{~cm}$ behind the unit.

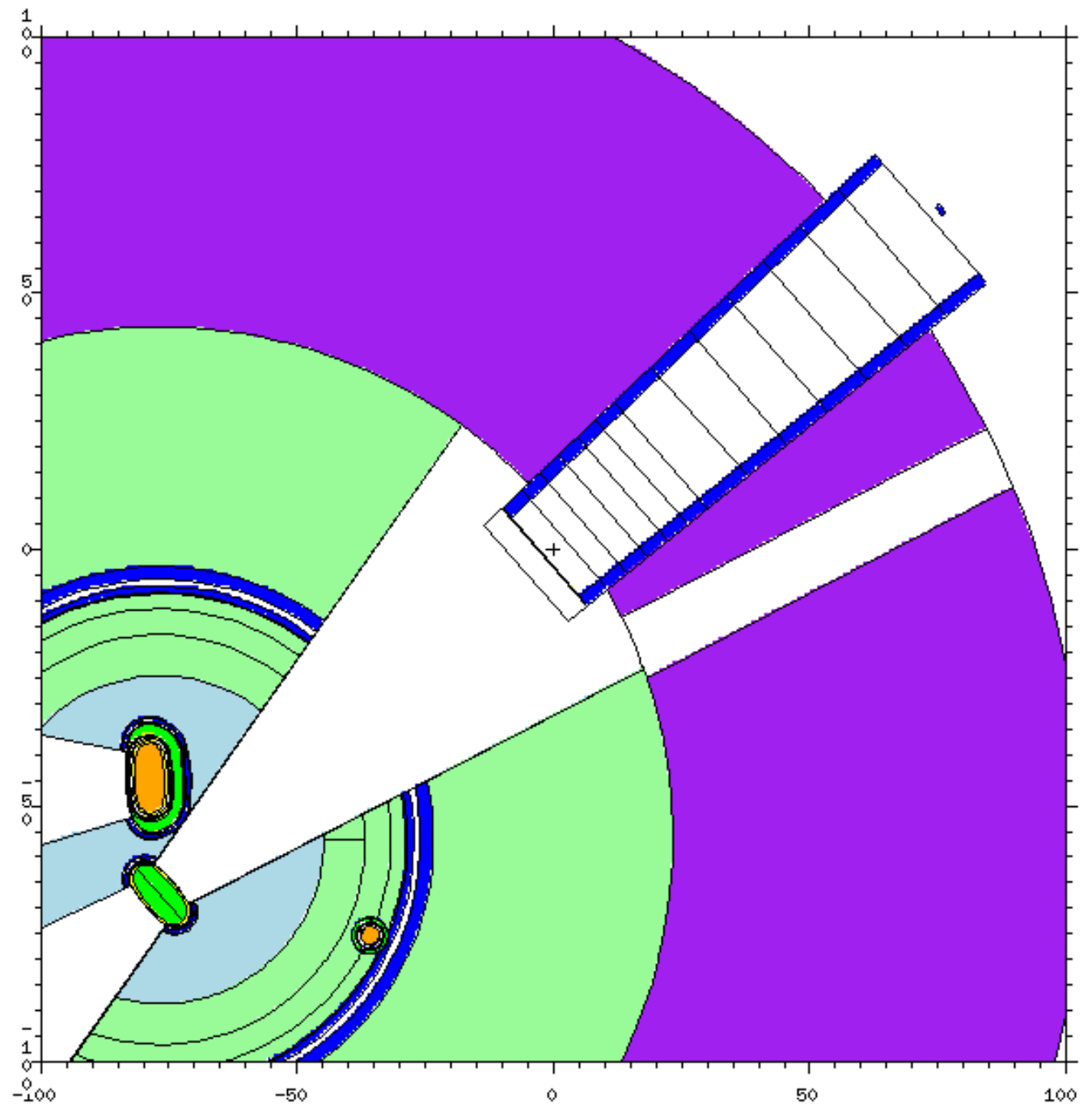

Fig. 10. Plan view of the multi core-vessel insert in beamline position number 8 . The proton beam enters from the bottom of the diagram thus placing the insert in a forward scattering position. 


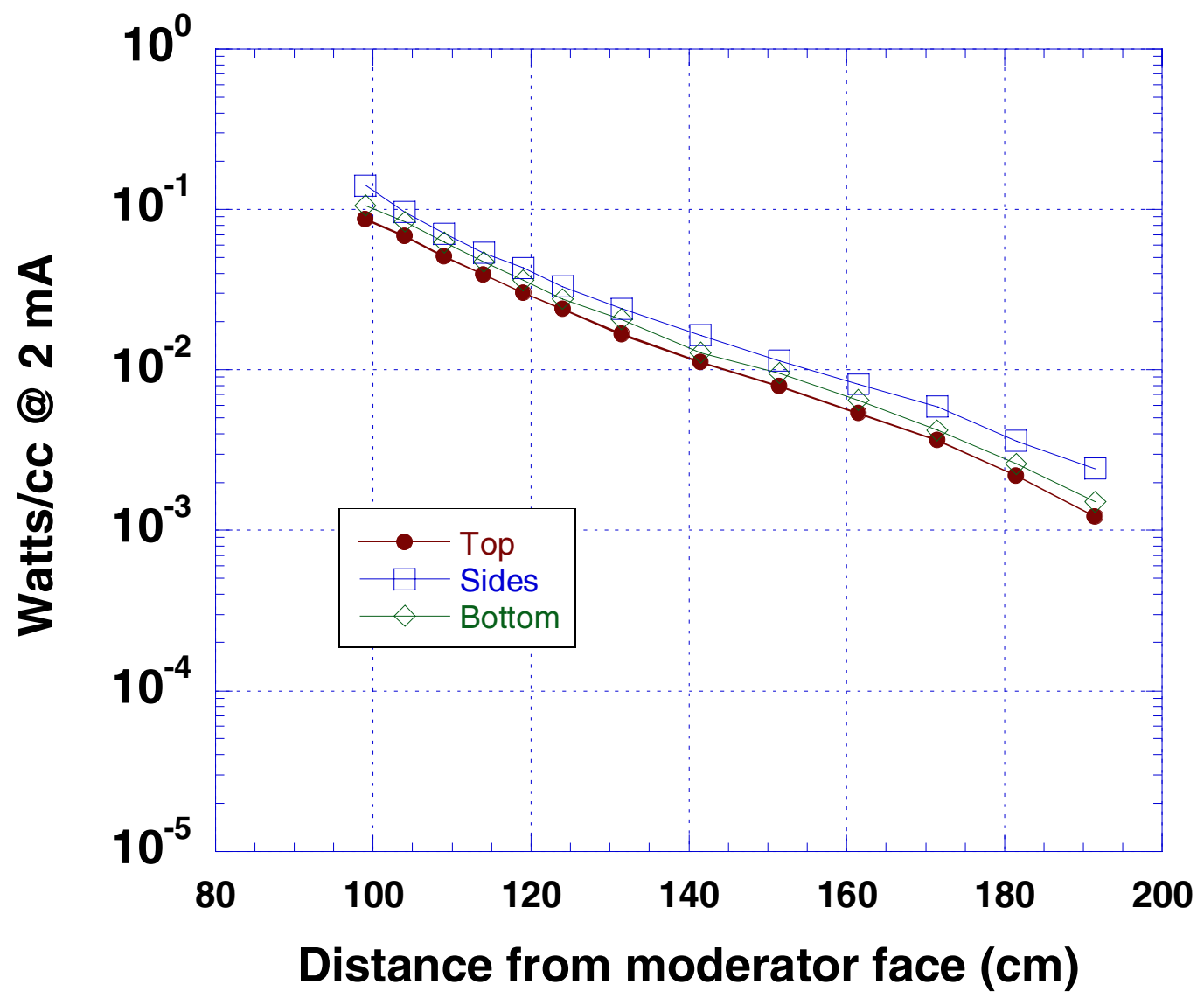

Fig. 11. Energy deposition along the top sides and bottom of the multi core-vessel insert. 


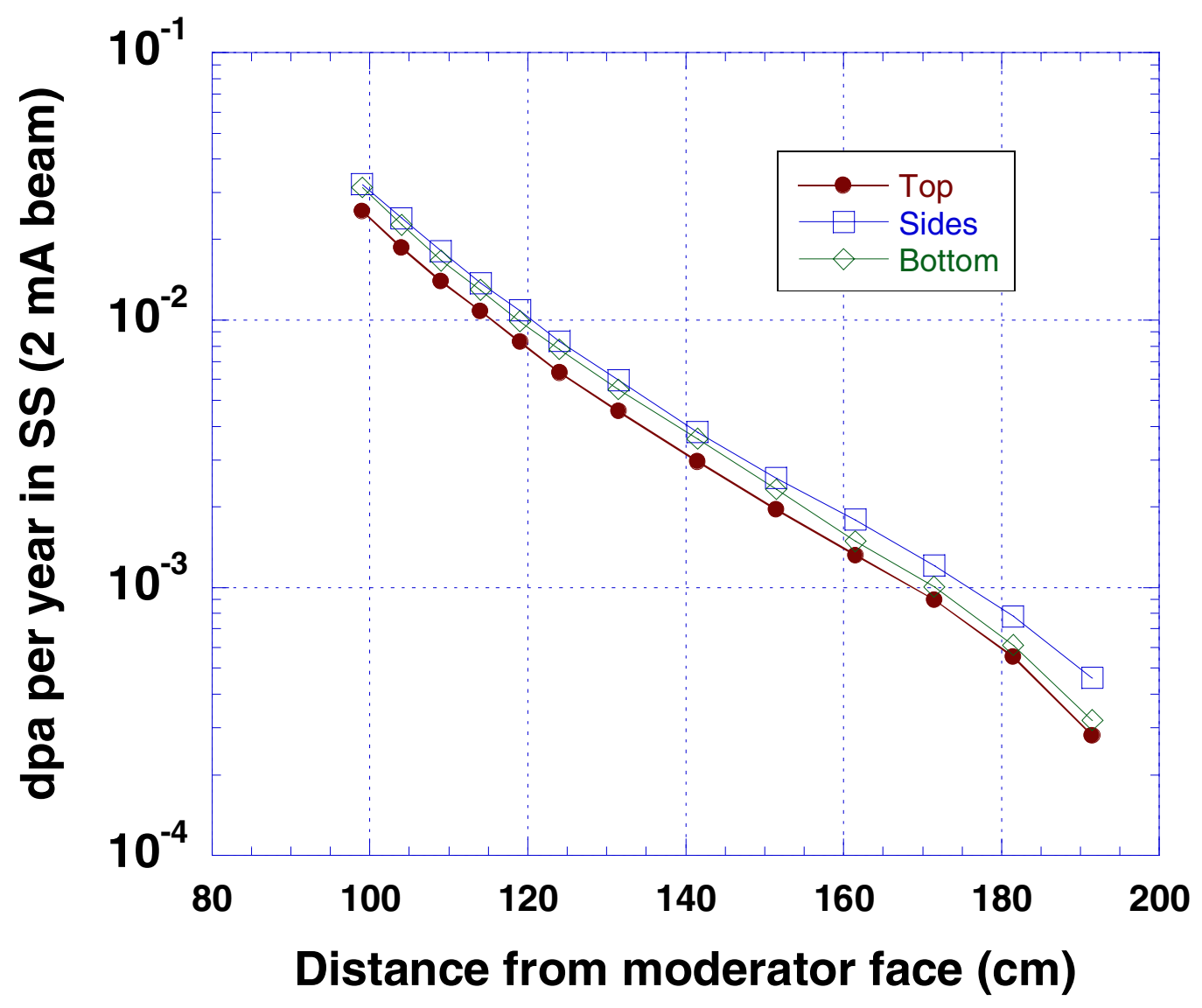

Fig. 12. Damage results for the dual-channel beam tube. 


\subsection{HARDENED STAINLESS STEEL COMPONENTS}

There are some hardened stainless steel components in both CVIs. These are associated with alignment features. This particular steel may be AISI E 52100 Steel or AISI 4140 Steel. Both are neutronically the same. For calculational purposes, we assumed 97\% iron, 1.5\% chromium, $1.0 \%$ carbon, and $0.5 \%$ manganese. We assumed a density of $7.83 \mathrm{~g} / \mathrm{cc}$.

Numerical results for the multi CVI, for stainless steel in the shutter region, and for hardened stainless steel are listed in Tables 5 and 6 at the end of this report. The numerical results for the hardened steel have been determined using the MCNP model of the multi unit. The values quoted are conservative and are also indicative of the energy deposition and damage for the hardened steel in the case of the single unit.

Table 5. Energy deposition in multi core-vessel insert

\begin{tabular}{|c|c|c|c|}
\hline $\begin{array}{l}\text { Distance } \\
(\mathrm{cm})\end{array}$ & $\begin{array}{c}\text { Top } \\
\text { (watts/cc) }\end{array}$ & $\begin{array}{r}\text { Bottom } \\
\text { (watts/cc) }\end{array}$ & $\begin{array}{c}\text { Sides } \\
\text { (watts/cc) }\end{array}$ \\
\hline 99.0 & 0.08702 & 0.10576 & 0.14001 \\
\hline 104.0 & 0.06773 & 0.08401 & 0.09677 \\
\hline 109.0 & 0.05099 & 0.06248 & 0.07090 \\
\hline 114.0 & 0.03921 & 0.04708 & 0.05385 \\
\hline 119.0 & 0.03017 & 0.03634 & 0.04301 \\
\hline 124.0 & 0.02382 & 0.02782 & 0.03306 \\
\hline 131.5 & 0.01663 & 0.02071 & 0.02412 \\
\hline 141.5 & 0.01109 & 0.01278 & 0.01655 \\
\hline 151.5 & 0.00788 & 0.00954 & 0.01141 \\
\hline 161.5 & 0.00537 & 0.00650 & 0.00814 \\
\hline 171.5 & 0.00367 & 0.00420 & 0.00590 \\
\hline 181.5 & 0.00219 & 0.00259 & 0.00361 \\
\hline 191.5 & 0.00122 & 0.00150 & 0.00244 \\
\hline \multicolumn{4}{|c|}{$\begin{array}{l}\text { Stainless steel } \\
\text { at shutter }\end{array}$} \\
\hline \multicolumn{4}{|c|}{ (watts/cc) } \\
\hline \multirow[t]{2}{*}{199.0} & \multicolumn{3}{|l|}{0.01076} \\
\hline & \multicolumn{3}{|c|}{$\begin{array}{l}\text { Hardened steel } \\
\text { (watts/cc) }\end{array}$} \\
\hline 224.0 & \multicolumn{3}{|l|}{0.00015} \\
\hline
\end{tabular}


Table 6. Damage in the multi core-vessel insert

\begin{tabular}{|c|c|c|c|}
\hline $\begin{array}{l}\text { Distance } \\
\quad(\mathrm{cm})\end{array}$ & $\begin{array}{c}\text { Top } \\
\text { (dpa/year) }\end{array}$ & $\begin{array}{l}\text { Bottom } \\
\text { (dpa/year) }\end{array}$ & $\begin{array}{c}\text { Sides } \\
\text { (dpa/year) }\end{array}$ \\
\hline 99.0 & 0.02556 & 0.03125 & 0.03222 \\
\hline 104.0 & 0.01856 & 0.02269 & 0.02405 \\
\hline 109.0 & 0.01395 & 0.01674 & 0.01808 \\
\hline 114.0 & 0.01079 & 0.01295 & 0.01370 \\
\hline 119.0 & 0.00828 & 0.00987 & 0.01085 \\
\hline 124.0 & 0.00636 & 0.00780 & 0.00835 \\
\hline 131.5 & 0.00458 & 0.00550 & 0.00598 \\
\hline 141.5 & 0.00296 & 0.00361 & 0.00382 \\
\hline 151.5 & 0.00196 & 0.00233 & 0.00257 \\
\hline 161.5 & 0.00132 & 0.00149 & 0.00180 \\
\hline 171.5 & 0.00090 & 0.00101 & 0.00121 \\
\hline 181.5 & 0.00055 & 0.00061 & 0.00078 \\
\hline \multirow[t]{2}{*}{191.5} & 0.00028 & 0.00032 & 0.00046 \\
\hline & \multicolumn{3}{|c|}{$\begin{array}{l}\text { Stainless steel } \\
\text { at shutter } \\
\text { (dpa/year) }\end{array}$} \\
\hline \multirow[t]{2}{*}{199.0} & 0.00098 & & \\
\hline & \multicolumn{3}{|c|}{$\begin{array}{l}\text { Hardened steel } \\
\text { (dpa/year) }\end{array}$} \\
\hline 224.0 & 0.0001 & & \\
\hline
\end{tabular}




\section{ACCURACY OF CALCULATIONS}

In discussing the accuracy of these calculations, it is important to distinguish between the real accuracy associated with the calculated numbers and the precision (or uncertainty) associated with the Monte Carlo transport process. The latter depends on the number of histories that are run in a given simulation and on the resulting neutron and photon flux in the regions of the geometry that are of interest (it is also dependent on the proper use of any variance-reduction techniques that may have been employed). Fluxes are significantly greater in regions of the inserts that are nearest to the target/moderator region. In most cases we have tried to achieve a precision of about 5\% where fluxes are highest and the precision may be around $20 \%$ to $30 \%$ in the parts of the insert body farthest from the target region. Probably the best qualitative indicator of precision can be obtained by observing the smoothness of the curves in the figures above.

In our opinion, the precision of these calculations is in all cases sufficient when one considers the accuracy of the cross sections that are the primary determinant of the overall accuracy or uncertainty. A reasonable estimate of the uncertainty associated with the energydeposition calculations is probably about $30 \%$. This estimate follows from previous experience with energy-deposition calculations and how the calculated values varied when different crosssection sets were used. However, to be on the cautious side, a 50\% uncertainty for energydeposition estimates is not unreasonable.

Damage estimates depend on one's ability to calculate displacements per atom (dpa). Different approaches yield displacement cross sections that can vary in some energy regions by a factor of a few or thereabouts. ${ }^{3}$ Furthermore, some damage cross sections were available to just $20 \mathrm{MeV}$. (The aluminum damage cross section was available to $800 \mathrm{MeV}$.) The contribution above $20 \mathrm{MeV}$ is, in most cases, quite small. This was true for stainless steel and glass (silicon damage cross sections were used). In our calculations, we chose the conservative approach of extrapolating the $20 \mathrm{MeV}$ cross section as a constant to higher energies. However, in the case of nickel, the damage cross section was found to be increasing as it approached $20 \mathrm{MeV}$ and different extrapolations above $20 \mathrm{MeV}$ added about $20 \%$ to $40 \%$ to the damage values. We chose the most conservative extrapolation for the nickel calculations. Thus, without embarking on a comprehensive uncertainty analysis effort, we refer back to the differences in various approaches used in the calculation of displacement cross sections. In light of this, it seems that engineering prudence indicates that a factor of two in uncertainty (or safety margin) should be associated with the damage values that have been calculated. 


\section{REFERENCES}

1. H. G. Hughes et al., "Recent Developments in MCNPX," p. 281 in Proc. of Second International Topical Meeting on Nuclear Application of Accelerator Technology, September 20-23, 1998, Gatlinburg, Tennessee.

2. P. D. Ferguson, Oak Ridge National Laboratory. Personal communication to B. D. Murphy, Oak Ridge National Laboratory, Oak Ridge, TN, January 2002.

3. E. J. Pitcher et al., "The Effect of the New Nucleon-Nucleus Elastic Scattering Data in LAHET Version 2.8 on Neutron Displacement Cross-Section Calculations," pp. 15-22.in Proc. of the Materials for Spallation Neutron Sources, the Minerals, Metals, and Materials Society (TMS), Warrendale, Pennsylvania (1998). 


\section{INTERNAL DISTRIBUTION}

1. W. C. Carter, 6011, MS-6370

2. K. W. Childs, 6011, MS-6415

3. P. D. Ferguson, 701SCA, MS-6474

4. F. X. Gallmeier, 701SCA, MS-6474

5. J. N. Herndon, 4500 N, MS-6228

6. E. B. Iverson, 701SCA, MS-6474

7. J. O. Johnson, 6025 , MS-6363

8. R. A. Lillie, 6025 , MS-6363

9. T. J. McManamy, 701SCA, MS-6474

10. B. D. Murphy, 6011, MS-6370

11. C. V. Parks, 6011, MS-6370
12. P. R. Summers, 701 SCA, MS-6474

13. D. M. Williams, 701SCA, MS-6474

14. ORNL Laboratory Records $4500 \mathrm{~N}, \mathrm{MS}-6254$

15. Central Research Library $4500 \mathrm{~N}, \mathrm{MS}-6191$

16. File-SNS DCC-RC

coxks1@sns.gov

\section{EXTERNAL DISTRIBUTION}

17. Doug Abernathy: dabernathy@anl.gov

18. John Ankner: jankner@anl.gov

19. James L. Bailey: jbailey@ anl.gov

20. Kent Crawford: rkcrawford@anl.gov

21. Tom Fornek: fornek@ anl.gov

22. Garrett Granroth: ggranroth@anl.gov

23. Ken Herwig: kherwig@anl.gov

24. Scott Keener: skeener@anl.gov

25. Roger Kellogg: rkellogg@anl.gov

26. Frank Klose: fklose@anl.gov

27. James Morgan: jmorgan@anl.gov

28. Xun-Li Wang: wangxl@ornl.gov

29. Jinkui Zhao: zhaoj@ornl.gov 
